Grand Valley State University

ScholarWorks@GVSU

$4-1-2010$

\title{
Delayed Enrichment of Mesenchymal Cells Promotes Cardiac Lineage and Calcium Transient Development
}

\author{
Liliana Grajales \\ University of Illinois at Chicago \\ Jesus Garcia \\ University of Illinois at Chicago \\ Kathrin Banach \\ University of Illinois at Chicago \\ David Geenen \\ Grand Valley State University, geenend@gvsu.edu
}

Follow this and additional works at: https://scholarworks.gvsu.edu/chm_articles

Part of the Medicine and Health Sciences Commons

\section{ScholarWorks Citation}

Grajales, Liliana; Garcia, Jesus; Banach, Kathrin; and Geenen, David, "Delayed Enrichment of Mesenchymal Cells Promotes Cardiac Lineage and Calcium Transient Development" (2010). Peer Reviewed Articles. 37. https://scholarworks.gvsu.edu/chm_articles/37

This Article is brought to you for free and open access by the Chemistry Department at ScholarWorks@GVSU. It has been accepted for inclusion in Peer Reviewed Articles by an authorized administrator of ScholarWorks@GVSU. For more information, please contact scholarworks@gvsu.edu. 
Original article

\title{
Delayed enrichment of mesenchymal cells promotes cardiac lineage and calcium transient development
}

\author{
Liliana Grajales a, Jesús García a, Kathrin Banach a,b, David L. Geenen a,b,* \\ ${ }^{a}$ Department of Physiology and Biophysics, Section of Cardiology and the Center for Cardiovascular Research, University of Illinois at Chicago, Chicago, IL 60612, USA \\ ${ }^{\mathrm{b}}$ Department of Medicine, Section of Cardiology and the Center for Cardiovascular Research, University of Illinois at Chicago, Chicago, IL 60612, USA
}

\section{A R T I C L E I N F O}

Article history:

Received 11 July 2009

Received in revised form 9 December 2009

Accepted 25 December 2009

Available online 6 January 2010

\section{Keywords:}

CD117

Bone marrow

Murine

Muscle

Stem cell

Differentiation

DHPR-alpha2

Myogenic

\begin{abstract}
A B S T R A C T
Bone marrow-derived mesenchymal stem cells (BM-MSCs) can be induced to differentiate into myogenic cells. Despite their potential, previous studies have not been successful in producing a high percentage of cardiac-like cells with a muscle phenotype. We hypothesized that cardiac lineage development in BM-MSC is related to cell passage, culture milieu, and enrichment for specific cell subtypes before and during differentiation. Our study demonstrated that Lin $^{-}$BM-MSC at an intermediate passage (IP; P8-P12) expressed cardiac troponin T (cTnT) after 21 days in culture. Cardiac TnT expression was similar whether IP cells were differentiated in media containing 5-azacytidine $+2 \%$ FBS (AZA; $14 \%$ ) or $2 \%$ FBS alone (LS; $12 \%$ ) and both were significantly higher than AZA $+5 \%$ FBS. This expression was potentiated by first enriching for CD117/Sca-1 cells followed by differentiation (AZA, 39\% and LS, 28\%). A second sequential enrichment for the dihydropyridine receptor subunit $\alpha 2 \delta 1$ (DHPR- $\alpha 2$ ) resulted in cardiac TnT expressed in $54 \%$ of cultured cells compared to $28 \%$ of cells after CD117/Sca- $1^{+}$enrichment. Cells enriched for CD117/Sca- 1 and subjected to differentiation displayed spontaneous intracellular $\mathrm{Ca}^{2+}$ transients with an increase in transient frequency and a 60\% decrease in the transient duration amplitude between days 14 and 29. In conclusion, IP CD117/ Sca- $1^{+}$murine BM-MSCs display robust cardiac muscle lineage development that can be induced independent of AZA but is diminished under higher serum concentrations. Furthermore, temporal changes in calcium kinetics commensurate with increased cTnT expression suggest progressive maturation of a cardiac muscle lineage. Enrichment with CD117/Sca-1 to establish lineage commitment followed by DHPR$\alpha 2$ in lineage developing cells may enhance the therapeutic potential of these cells for transplantation.
\end{abstract}

(c) 2010 Elsevier Ltd. All rights reserved.

\section{Introduction}

Bone marrow-derived mesenchymal stem cells (BM-MSCs) exhibit neurogenic, chondrogenic, adipogenic, osteogenic, and myogenic properties under specific differentiating conditions in vitro. Although these cells have contributed to improvement in overall cardiac performance in studies of myocardial regeneration, the mechanisms responsible for their therapeutic effects are not well established. BM-MSCs are characterized as a small percent of lineage negative ( $\mathrm{Lin}^{-}$) adherent cells, and their myogenic lineage potential is highly dependent on the enrichment for specific markers following harvesting. Published results have shown that further enrichment of Lin $^{-}$cells for the CD117 and Sca-1 membrane surface markers may improve BM-MSC ability to differentiate into cardiomyocytes [1-5]. Furthermore, cell surface markers such as CD117 change over time [2, 6] and from passage to passage in cultured cells. Thus, we hypothesize that in murine BM-MSC, differentiation into cardiomyocytes is

\footnotetext{
* Corresponding author.

E-mail address: geenen@uic.edu (D.L. Geenen).
}

dependent on cell passage and the potential for differentiation is greater in early passage cells $(P \leq 12)$ compared to late passage cells $(P \geq 20)$.

Previous studies indicate that there is no well-defined and consistent myogenic differentiation method. Some methods involve the use of 5-azacytidine (AZA), a methyltransferase inhibitor. Although this reagent induces myogenic development [7-9], it has limited use in human cell therapy. Other differentiation protocols that induce myogenic commitment in BM-MSC include the use of TGF-beta [6] and neonatal or adult cardiomyocyte co-cultures [10-13]. A recent report on human embryonic stem cells (hESC) demonstrated that hESC cardiomyocyte differentiation increased when the cells were cultured in serum-free media compared to $20 \%$ serum in the media [14]. Thus, we also propose to evaluate BM-MSC differentiation in low serum (LS) media and compare it to AZA treatment.

We demonstrate here for the first time that CD117/Sca-1 enrichment following passage 10 in Lin $^{-}$murine BM-MSC results in increased sarcomeric protein expression and spontaneous calcium transients that change over time in culture when differentiated in low serum. Furthermore, we show that a subsequent second enrichment for the dihydropyridine receptor subunit $\alpha 2 \delta 1$ (DHPR- $\alpha 2)$ and cell 
replating induces a greater expression of cardiac TnT expression than with CD117/Sca-1 enrichment alone. Thus, we defined specific steps that allow an enhanced differentiation of BM-MSC into cardiomyocytes.

\section{Materials and methods}

\subsection{Animals}

Mice were housed in the Biological Resources Laboratory at UIC (AAALAC accredited) and maintained in accordance with the Guide for the Care and Use of Laboratory Animals (National Research Council, revised 1996). Experimental protocols were approved by the Institutional Animal Care and Use Committee (IACUC) at UIC.

\subsection{Bone marrow mesenchymal stem cell (BM-MSC) characterization and culture}

Bone marrow was isolated from FVB.Cg-Tg(GFPu)5Nagy/J mice (Jackson Laboratory) as previously described [15]. Tibia and femur bones were stripped of muscle and placed in ice-cold PBS $+2 \%$ FBS. The epiphyseal ends were removed and the bones were centrifuged at $4000 \times g$ for $1 \mathrm{~min}$ in a microfuge tube. The bone marrow cells were suspended in ice-cold PBS $+2 \%$ FBS, passed through a $70-\mu \mathrm{m}$ filter and counted with a hemocytometer.

Filtered bone marrow cells were suspended in PBS $+2 \%$ FBS + $0.1 \mathrm{~g} / \mathrm{L}$ phenol red and enriched for lineage negative ( Lin $^{-}$) cells using the SpinSep system (Stem Cell Technologies). The cells were incubated with Murine Progenitor Enrichment Cocktail (anti-CD5, anti-CD45R, anti-CD11b, anti-Gr-1, anti-TER119, and anti-7/4; Stem Cell Technologies) on ice for $30 \mathrm{~min}$ and, after washing, incubated with dense particles on ice for $20 \mathrm{~min}$. The cells were layered on density medium, centrifuged at $1200 \times \mathrm{g}$ for $10 \mathrm{~min}$, and the layer of cells at the density medium/PBS interface was collected, washed, and counted.

Enriched bone marrow cells were seeded on tissue culture-treated plates at a density of $0.1 \times 10^{6}$ cells $/ \mathrm{cm}^{2}$ in murine Mesencult media (Stem Cell Technologies) with $100 \mathrm{U} / \mathrm{ml}$ penicillin, $100 \mu \mathrm{g} / \mathrm{ml}$ streptomycin, and $0.25 \mu \mathrm{g} / \mathrm{ml}$ amphotericin B added. The media were changed after $48 \mathrm{~h}$ and adherent cells were maintained in culture with twice weekly media changes. After 4 weeks the confluent cells were detached with trypsin and split 3:1. Lin ${ }^{-}$MSCs were characterized for surface antigens using flow cytometry. Antibodies were obtained from BD Pharmingen unless otherwise noted. Cultured cells were detached with trypsin and incubated with $1 \mu \mathrm{l}$ mouse Fc block (1:50 dilution; clone 2.4G2, rat anti-mouse CD16/CD32) for 5 min on ice. Cells were then incubated with $1 \mu \mathrm{l}$ fluorescent-conjugated antibodies (1:50 dilution) for $1 \mathrm{~h}$ on ice, washed, and analyzed.

The following mouse monoclonal antibodies were used: antiCD45-Cy5 (clone 30-F11), anti-Sca1-PE (clone E13-161.7), antiSca1-Cy5 (clone D7; eBioscience), anti-CD34-PE (clone RAM34), anti-CD90.1-PE (clone HIS51), anti-CD117(cKit)-PE (clone 2B8), antiCD105-biotin (clone MJ7/18; eBioscience). Those treated with biotinylated antibodies were washed and incubated 20 min at room temperature with $1 \mu \mathrm{l}$ streptavidin-PE or streptavidin-Cy5. Control samples were treated with immunoglobulin of the appropriate isotype. Cells were analyzed in a (FACS) Calibur flow cytometer or in a Beckman Coulter FC500 equipped with one (Calibur) or two lasers (Beckman) for multiparametric and multicolor analysis, including a 488-nm argon laser for measurement of forward light scatter (FSC) and orthogonal scatter (SSC), and three to five colors.

\subsection{BM-MSC cardiomyocyte differentiation}

BM-MSCs were plated (BD Falcon slides 354112 and Bioptech Tdish $0420041500 B$ ) at a density of 8000 cells per well for early passage cells (EP: P0-P2). All intermediate passages (IP: P8-P12) and late passage (LP: P20 and above) cells were plated at a density of 3000 cells per well $\left(4 \mathrm{~cm}^{2}\right)$. Cells were allowed to attach to the plate by culturing them for $24 \mathrm{~h}$ in Mesencult with supplements. After adhering, cells were treated with one of five differentiating media for 19-21 days (Fig. S1). AZA-treated cells were cultured with $1.2 \mu \mathrm{M}$ AZA in Eagle's MEM with 2\% FBS for 72 h (Sigma: 5-azacytidine, A2385, MEM, M0643 with $2.2 \mathrm{~g}$ sodium bicarbonate Invitrogen: Certified Fetal Bovine Serum 16000-044). Low serum (LS)-treated cells were cultured in Eagle's MEM with $2 \%$ FBS for 72 h. Cells were also treated for $72 \mathrm{~h}$ with AZA alone and AZA with $5 \%$ serum. After $72 \mathrm{~h}$, the media in the four AZA and/or LS groups were replaced every 2 to 3 days using MEM with $5 \%$ FBS and $5 \mu \mathrm{g} / \mathrm{ml}$ of insulin and transferrin, $5 \mathrm{ng} / \mathrm{ml}$ of sodium selenite (Sigma: ITS, I1884 prepared as recommended). A fifth group of cells was treated with MEM and 5\% FBS for the entire 19-21 days.

\subsection{CD117/Sca-1 FACS analysis and enrichment}

Following the differentiation period, cells were detached with $0.25 \%$ trypsin and incubated in FACS buffer (PBS with 2 mM EDTA and $0.25 \%$ BSA) with $1 \mu$ l anti-mouse IgG (Sigma: M0284, Fc block, 1:50 dilution) for $5 \mathrm{~min}$ on ice. Cells were then incubated with $1 \mu \mathrm{l}$ fluorescent-conjugated antibodies for Sca-1 (Bioscience: PE-Cy5 Ly6A/E 155981-81) and CD117 (BD Pharmingen: PE anti-mouse CD117 clone 2B8) for $1 \mathrm{~h}$ on ice, washed and analyzed. EP, IP, and LP cells were analyzed for the presence of CD117 and Sca-1 and their results are shown in Figs. S2A, B, and C, respectively. Although EP cells exhibited the highest percentage of $\mathrm{CD} 117 / \mathrm{Sca}-1^{+}$cells compared to IP and LP in our initial FACS analysis, we were unable to maintain them as adherent cells in culture and therefore unable to assess the potential of enriched cells from EP to differentiate and express cTnT. LP cells although adherent after differentiation were negative for CD117/Sca-1. Thus, we focused on the IP cell cultures which were both adherent and contained sufficient CD117/Sca- $1^{+}$cells to assess the potential for myogenic development. IP cells at P8 were analyzed and enriched for CD117 and Sca-1 and cultured in Mesencult with supplements. The expanded enriched cells (P10) were analyzed a second time for the presence of CD117 and Sca- 1 at the time of differentiation and their FACS results are shown in Fig. S2D.

\subsection{Immunofluorescent staining}

Differentiated cells were stained for cardiac-specific Troponin T, cardiac isoform Ab-1 (cTnT; Thermo Scientific MS-295-P0). The cells were fixed with $2 \%$ paraformaldehyde for $20 \mathrm{~min}$. We used horse serum $(5 \%)$ diluted in $0.1 \%$ Tween in PBS for blocking and permeabilization for $45 \mathrm{~min}$. Additional blocking with avidin and biotin agents (Vector Labs, SP2001) was performed for 15 min each. The primary cTnT was mixed with ready to use ultra Ab diluent (Thermo Scientific, TA-125-UD, in a ratio of 1:200) and incubated overnight at $4{ }^{\circ} \mathrm{C}$. Biotinylated horse anti-mouse IgG (Vector Labs BA2001) was used as the secondary ( $1 \mathrm{~h}$ at RT, 1:250), and streptavidin Alexa Fluor 555 or 633 conjugate (Invitrogen: S21381, S21375,1:1000) was used for fluorescent detection (15 min at room temp). After washing, cells were mounted with DAPI (Vector Laboratories, Inc). For the isotype controls, we used IgG1 (R\&D Systems: MAB 002, 1:200). For DHPR- $\alpha 2$ staining, we used the same procedure described above except that DHPR- $\alpha 2$ (ABR-Thermo Fisher: MA3-921, 1:300) was used as the primary antibody.

\subsection{DHPR- $\alpha 2$ enrichment of differentiated cells}

After 26 days in culture, differentiated cells were lifted from the plate with enzyme-free dissociation buffer (Gibco: 1752). Cells were washed and re-suspended in a buffer mixture of 50\% MEM and 50\% 
FACS buffer. Cells were incubated for 90 min with the primary antibody (ABR-Thermo Fisher: mouse anti-DHPR- $\alpha 2$, MA3-921) at a concentration of $3 \mu \mathrm{l}$ per $2 \times 10^{6}$ cells and placed on ice. Cells were washed with the MEM buffer mixture and incubated for $1 \mathrm{~h}$ with the secondary antibody (goat anti-mouse-IgG1 Cy5, Jackson Immuno Research, PA No115-175-205) at a concentration of $3 \mu \mathrm{l}$ per $2 \times 10^{6}$ cells on ice. Cells were washed, re-suspended, filtered (70 $\mu \mathrm{m})$, and FACS selected for DHPR- $\alpha 2$-positive cells. DHPR- $\alpha 2$ enriched cells were plated at the same density as the originally differentiated cells (3000 cells per $\mathrm{cm}^{2}$ ) and cultured for an additional 30 days. In a separate experiment we added two control groups, one in which we left the differentiated cells in culture for a total of 56 days and a second in which we lifted the cells at day 26 and replated (3000 cells per $\mathrm{cm}^{2}$ ) them for an additional 30 days. Thus, we could examine the effects of both length of time in culture and lifting/replating the cells on cTnT expression.

\subsection{Intracellular calcium $\left(\mathrm{Ca}^{2+}\right)$ measurements}

Differentiated cells plated in $0.17 \mathrm{~mm}$ thick Bioptechs Delta T dishes and incubated with MEM and 5\% FBS media and a calciumsensitive dye (Fluo-4/AM, Invitrogen: F1420, $5 \mu \mathrm{M}$ ) . The dye was prepared by dissolving $50 \mu \mathrm{g}$ of fluo-4/AM in $50 \mu \mathrm{l}$ of DMSO and $50 \mu \mathrm{l}$ of 20\% Pluronic F-127 and $400 \mu$ of Tyrode's salt solution [16] (Sigma: T2145, with $1 \mathrm{~g}$ of sodium bicarbonate and $\mathrm{pH}$ set to 7.4 for $15 \mathrm{~min}$ at room temperature). Thereafter, cells were washed and incubated with new MEM media and allowed to rest for 15 min for de-esterification of the dye. For viewing, the media was replaced with Tyrode's salt solution. Calcium cycling cells were identified and selected for line scan analysis (Zeiss LSM 510). The sampling time of the scan was between 3.7 and $7.8 \mathrm{~ms}$ per line depending on the cycling rate of the selected cell. Fluo-4/AM was excited at $488 \mathrm{~nm}$ and the emission was collected above $515 \mathrm{~nm}$. The parameters extracted from the generated curves were (1) $\mathrm{Ca}^{2+}$ transient frequency in Hertz, (2) $\mathrm{Ca}^{2+}$ transient duration at $50 \%$ amplitude in milliseconds, $\mathrm{TD}_{50}$, and (3) $\mathrm{Ca}^{2+}$ transient duration at $90 \%$ amplitude in milliseconds, $\mathrm{TD}_{90}$.

\section{8. cTnT-positive cell count and morphology}

For positive cTnT cell count, fields of view within a slide were randomly selected throughout the slide where cells were present. Nucleus (DAPI staining) and cTnT (Alexa Fluor 555) images were taken for each field with a Sony camera (DSC-H9). All images were originally stored in bit map format and filtered utilizing Image $(\mathrm{NIH}$. gov) for cell counting. The percentage of cTnT-positive cells was obtained after comparing the number of positive cells with the number of nucleus in a field.

For area measurements, fields of view were randomly selected throughout the slide where cTnT-positive cells were present. Nuclei (DAPI staining) and cTnT (Alexa Fluor 633) images were taken for each field with a Zeiss confocal microscope with the cTnT color set to green. Only cells aligned with the surface of the focal plane (those having a defined nucleus) were measured. We used the analyze particles tool from ImageJ (NIH software) to measure the cell area. The average areas and the standard deviations at each of the time points measured were divided by the average area of cells at day 5 to compare cell area growth.

\subsection{RT-PCR and CDNA sequencing}

Total RNA was obtained from IP CD117/Sca-1-enriched cells differentiated in 2\% FBS at days 5, 15, 20 and 26 and adult cardiac tissue using the Trizol ${ }^{\circledR}$ reagent (Gibco: No 15596) protocol for suspended cells (BM-MSCs) and tissue protocol for the adult heart. The RNA eluate was reverse transcribed using $5 \mu \mathrm{l}$ of RNA and $200 \mathrm{U}$ of MMLV RT reverse transcriptase and random hexamers (Invitrogen: No
8080127). PCR was performed with Taq DNA Polymerase (Fermentas: No. EP0402) and gene-specific primers 18 to 27 nucleotides in length. The total PCR volume was $50 \mu \mathrm{l}$, with $1 \mu \mathrm{l}$ of the amplified cDNA, $1 \times$ PCR buffer, $0.2 \mathrm{mM}$ of dNTP, $2 \mathrm{mM}$ of $\mathrm{MgCl} 2,2.5 \mathrm{U}$ of Taq DNA polymerase, and $0.4 \mu \mathrm{M}$ of primer (see sequences below). PCR products were sizefractionated by $2 \%$ agarose gel electrophoresis. The primer sequences were as follows: for DHPR- $\alpha 2$ (forward) GGC CGG ATC CGC AAT TGA TCC TAA TGG and (reverse) GAA GGC TGC AGA TCAT TGC AGT ATTC; for CTnT (forward) TGC ACT TTG GAG GGT ACATC and (reverse) GTC TTC ATT CAG GTG GTC GA; for CTnI (forward) GCT CCT CTG CCA ACT ACCGA and (reverse) CAA CGA GTC CTCA GAA CGCG; for GATA-4 (forward) GAA CCT GAA TAA ATC TAA GACGC and (reverse) TCT GAG TGA CAG GAG ATG CATA; and for GAPDH (forward) TAT GAC AAT GAA TAC GGCT and (reverse) CTC CTG TTA TTA TGG GGG.

\subsection{Fluo4/AM-loaded BM-MSCs in the presence of nifedipine and cadmium}

DHPR- $\alpha 2$-enriched cells were loaded with Fluo-4/AM and incubated with Tyrode's salt solution. Initial video recordings of $\mathrm{Ca}^{2+}$ cycling were taken while the cells were in Tyrode's salt and electrically stimulated with a 5-ms pulse at $80 \mathrm{~V}$ and a frequency of $1.0 \mathrm{~Hz}$. After $10 \mathrm{~s}, 40 \mu \mathrm{M}$ nifedipine (Sigma: No. 7624) dissolved in Tyrode's solution was applied drop wise while removing the original Tyrode's with a peristaltic pump. The video recorded continuously during the test; however, the light source was periodically removed to reduce fluorescence bleaching. Similarly, confocal line scans of selected calcium cycling cells were taken (166 samples per second) at different time periods during the nifedipine application. The transient amplitude TA $\left[\left(\Delta F=F_{\max }-F_{\min }\right) / F_{0}\right]$ was calculated, where $F$ is the amplitude value after background subtraction and $F_{0}$ is the minimum value of the first calcium cycle. An additional video recording was made of DHPR- $\alpha 2$-enriched cells previously loaded with Fluo-4/AM after application of $100 \mu \mathrm{M} \mathrm{CdCl}_{2}$ (Fisher Scientific: C9-100) dissolved in Tyrode's salt solution.

\subsection{Statistical data analysis}

Values are presented as means \pm SEM and $n$ is the number of experiments. The significant differences between groups were evaluated using SigmaStat (Systat Software Inc.). Groups with unequal variances were analyzed using the Kruskal-Wallis Test, and post hoc multiple comparisons between groups were performed with Dunn's method. For experiments where only two sets of data were compared, we used the Mann-Whitney rank sum test method. A result of $p<0.05$ was considered statistically significant.

\section{Results}

\subsection{BM-MSC flow cytometry and passage selection}

In preparation for our experiments, MSCs were analyzed by flow cytometry for the presence of various surface antigens after negative lineage selection and following two different passages in culture. Negative selection for the lineage markers CD5, CD45R, CD11b, Gr-1, TER119, and 7/4 resulted in a cell population containing CD34 (3\%), CD 90.1 (34\%), CD105 (23\%), CD117 (43\%), and Sca-1 (21\%). Passage 4 Lin $^{-}$adherent BM-MSC exhibited an increased Sca-1 and CD105 population (91\% and 60\%, respectively) while CD34-, CD90.1-, and CD117-positive cells were low. Passage 17 BM-MSC continued to be strongly Sca-1 positive but CD117 low. There was a dramatic increase in CD34 by passage 17 so that $80 \%$ of the cells were positive for this antigen. These data confirm the changing characteristics of MSC in culture and further underscore the importance of FACS analysis and enrichment for specific cell surface receptors prior to beginning interventions with these cells. Previous studies have shown that a 
small percentage of BM-MSCs differentiate into cardiac-like cells. Thus, we set up a series of experiments aimed at increasing the cTnTpositive cell percentage by evaluating culture milieu and enrichment for specific cell markers in IP cells before differentiation. In the first series of experiments, we determined whether BM-MSC passage selection would influence the expression of cTnT in cells when subjected to myogenic differentiation. Three Lin $^{-}$BM-MSC passages were used: early passage (EP: P0-P2), intermediate passage (IP: P812), and late passage (LP: P20) utilizing AZA or LS treatment. EP cells were very slow to proliferate, and the few cells that remained attached were $\mathrm{cTnT}^{-}$after 3 weeks of AZA or LS differentiation treatment. Differentiating IP cells were $\mathrm{cTnT}^{+}$within 3 weeks of treatment (AZA: $14 \pm 1 \%$, LS: $12 \pm 2 \%, n=53$ and 46 , respectively) while LP cells were $\mathrm{CTnT}^{-}$over the 3 -week period of AZA or LS treatment. Figs. S3A, B, and C illustrate cTnT staining results of EP, IP, and LP cells after LS differentiation treatment.

Since it has been demonstrated that $\mathrm{Sca}-1^{+}$cells possess stemprogenitor properties $[17,18]$ and that $\mathrm{CD} 117^{+}$cells have the potential to differentiate into a cardiac lineage [12], we used FACS analysis to evaluate the amount of CD117/Sca-1 initially present on EP, IP, and LP. The results indicated that approximately $10 \%$ of EP cells were positive for CD117/Sca-1, whereas IPs exhibited approximately $1 \%$ of CD $117 / \mathrm{Sca}-1^{+}$, and LPs only $0.01 \%$ of CD $117 /$ Sca- $1^{+}$cells; Figs. S2A, B, and C show the FACS results of EP, IP, and LP, respectively.

\subsection{CD117/Sca-1 enrichment and differentiation media}

In our second series of experiments, we enriched both EP and IP cells for CD117/Sca-1. EP cells were not adherent following enrichment. Although our FACS results indicated that EP cells have the highest number of CD117/Sca- $1^{+}$cells, their differentiation might be attenuated due to their low proliferation rate and attachment. To further evaluate the differentiation potential of murine BM-MSC, we therefore focused on the IP cells in the remaining series of experiments.

To improve the percentage of cTnT-positive cells, we enriched IP cells for CD117/Sca-1 and used the five differentiation conditions described in the Materials and methods section (see also Fig. S1). IP Lin ${ }^{-}$, BM-MSCs were enriched for CD117/Sca-1 at passage 8 , seeded and then cultured with differentiation media until passage 10. By passage 10 , these cells were $40 \% \mathrm{CD} 117^{+}$and $99 \% \mathrm{Sca}-1^{+}$as shown in Figs. S2D and E. IP CD117/Sca- ${ }^{+}$cells and IP control (nonenriched), cells were cultured for differentiation for up to 21 days in different combinations of AZA or LS. Fig. 1 provides a summary of the overall series of experiments performed based on cell passage and enrichment for CD117/Sca-1. Cell counts of microscopic fields of these differentiated cells revealed that the enriched cells had $39 \pm 3 \%$ and
$28 \pm 2 \%$ cTnT-positive expression compared to the non-enriched control cells which had $14 \pm 1 \%$ and $12 \pm 2 \%$ after treatment with AZA and LS, respectively, as shown in Fig. 2. A magnification of IP CTnT $^{+}$ cell staining is shown in Fig. S4. Separately, IP CD117/Sca- $1^{+}$cells that were treated with control culture medium (MEM and 5\% FBS) only exhibited $18 \pm 3 \%$ cTnT-positive cells, significantly less than in AZA or LS-treated cultures (see Fig. S5). These results support the hypothesis that CD117/Sca-1 enrichment of murine BM-MSC increases their differentiation potential in specific media. The percent of $\mathrm{cTnT}^{+}$cells in the AZA $+0 \%$ and $5 \%$ FBS groups were expressed as a ratio of the $A Z A+2 \%$ FBS group used in our experiments. There was no difference between AZA with $0 \% \mathrm{FBS}$ and AZA with $2 \% \mathrm{FBS}$. AZA with $5 \% \mathrm{FBS}$ had a significantly lower ratio of $\mathrm{CTnT}^{+}$cells compared to the AZA $+2 \% \mathrm{FBS}$ group (Fig. S6). Thus, we concluded AZA did not significantly improve cTnT expression compared to 2\% FBS alone but that serum levels above $2 \%$ in the differentiating media significantly decreased the expression of $\mathrm{cTnT}$.

\subsection{Temporal changes in expression of cTnT and BM-MSC morphology}

To determine how differentiated BM-MSC change in size over time, we fixed IP CD117/Sca- $1^{+}$cells differentiated in LS at different intervals of time in culture. Figs. 3A-D illustrate representative immunofluorescent images of cTnT staining observed on day 5, day 9 , day 15 , and day 21 , respectively. Fig. $3 E$ shows the area growth of the cTnT-positive cells relative to day 5 . It can be seen that there was near zero increase in the area growth of the cells between day 5 and day 15 ; however, there was a $1.83 \pm 0.21$-fold increase in the cell area between day 15 and day 21 . These results suggest that the maturation process of differentiated $\mathrm{cTnT}^{+}$cells includes a period of cell area expansion after 15 days in culture.

\subsection{Temporal changes in intracellular $\mathrm{Ca}^{2+}$ transients}

It has been previously reported that differentiating stem cell derived cardiomyocytes early on exhibit spontaneous oscillations in their intracellular $\mathrm{Ca}^{2+}$ concentration [16]. To determine if LS differentiated IP CD117/Sca- ${ }^{+}$cells exhibited the same properties, we monitored the cells $\left[\mathrm{Ca}^{2+}\right]_{i}$ with laser scanning confocal microscopy. By day 12, cells exhibited intermittent transients with short durations (see Fig. S8), whereas by day 14, the recorded transients were consistent in rhythm and duration. We chose day 14 as our baseline and recorded confocal line scans again at days 19 and 29 of differentiation and evaluated their characteristics to determine temporal changes in the intracellular $\mathrm{Ca}^{2+}$ transients. Figs. $4 \mathrm{~A}$ and $\mathrm{B}$ show representative line scans at day 14 and day 29. Analyses of spontaneous intracellular $\mathrm{Ca}^{2+}$ transients show a decrease in the

\begin{tabular}{|c|c|c|c|}
\hline \multirow[b]{2}{*}{$\begin{array}{l}\text { Differentiation media for } \\
\qquad 21 \text { days }\end{array}$} & \multicolumn{3}{|c|}{ Lin Cells } \\
\hline & $\begin{array}{c}\text { Early Passage } \\
\text { (EP) } \\
\text { P0 - P2 } \\
\end{array}$ & \begin{tabular}{|c|} 
Intermediate \\
Passage (IP) P10 \\
- P12 \\
\end{tabular} & $\begin{array}{l}\text { Late Passage } \\
\text { (LP) } \\
\text { P20 } \\
\end{array}$ \\
\hline Result & $\mathrm{cTnT}$ & $\mathrm{cTnT}^{+}$ & cTnT \\
\hline CD117/Sca-1 enrichment & $\begin{array}{l}\text { EP enriched } \\
\text { cells did not } \\
\text { attach }\end{array}$ & $\begin{array}{l}\text { P8 enriched, P9 } \\
\text { proliferated, IP } \\
\text { differentiated }\end{array}$ & $\begin{array}{l}\text { LP gave too low } \\
\text { CD117/SCA }\end{array}$ \\
\hline $\begin{array}{c}\text { Result } \\
\text { (differentiation } 21 \text { days) }\end{array}$ & & $\mathrm{cTnT}^{+}$ & \\
\hline
\end{tabular}

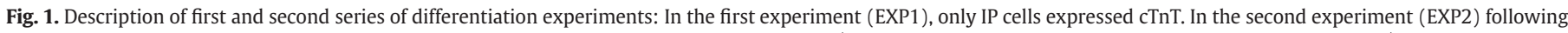

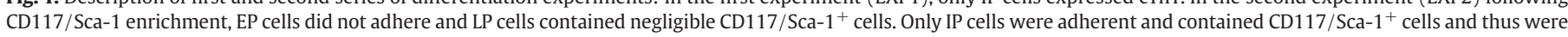
used for the remaining experiments. 
A

\section{CTIT DAPI}

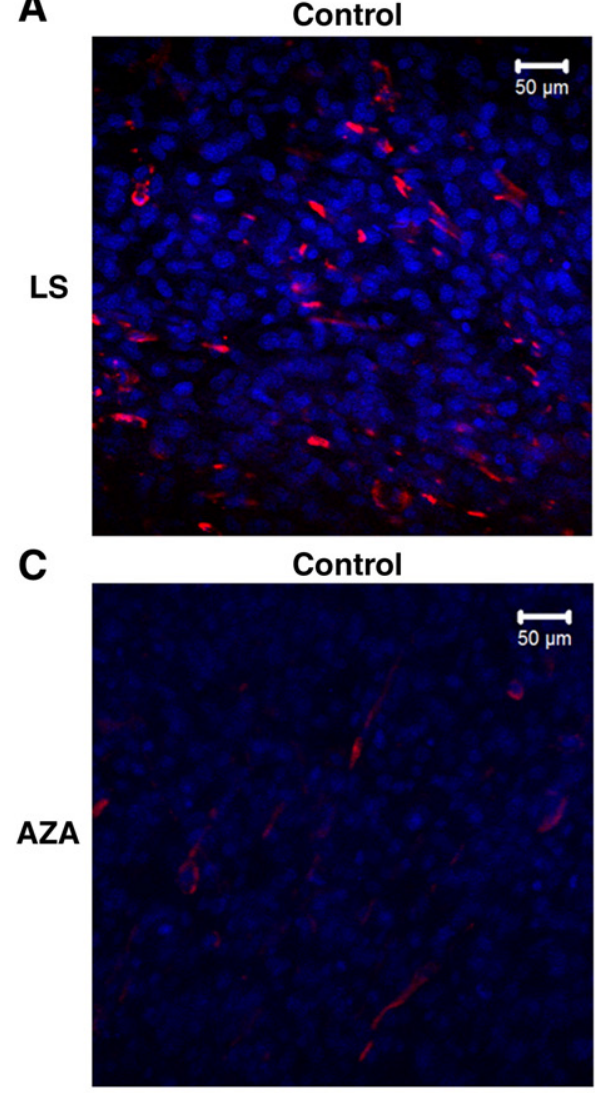

E
B

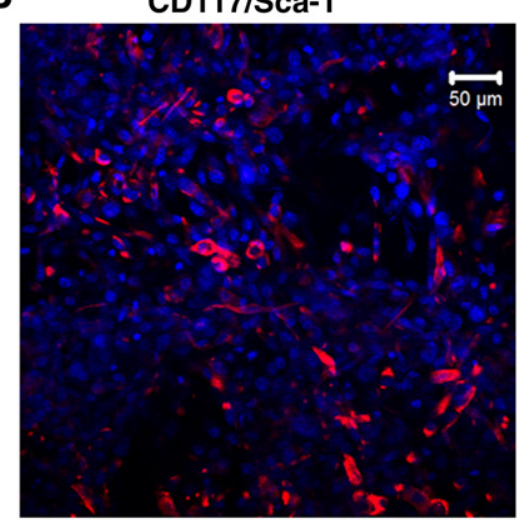

D

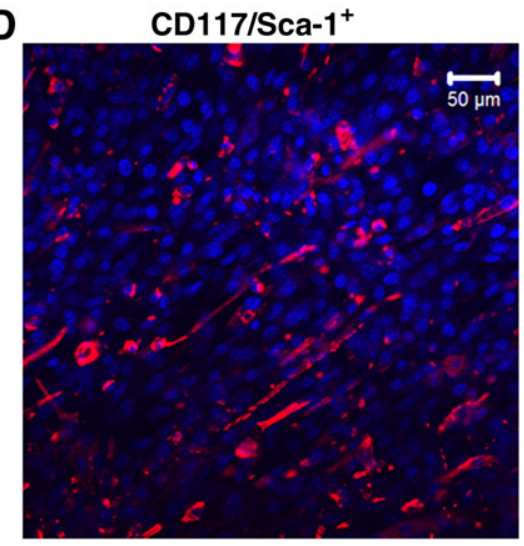

$\square \mathrm{CD} 117 / \mathrm{SCA}-1^{+}$

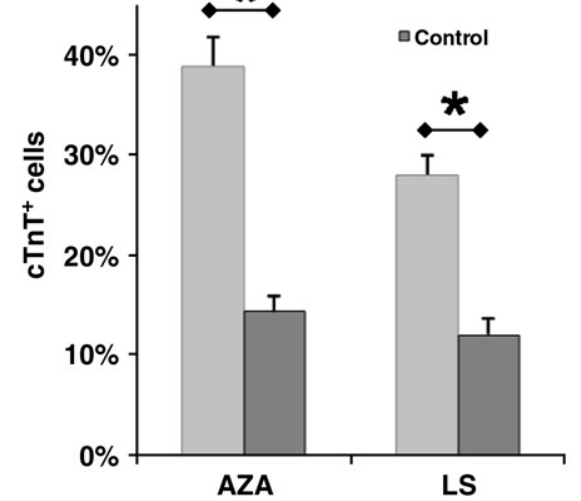

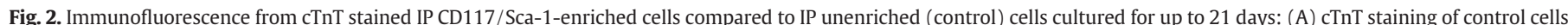

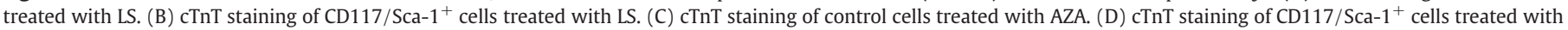

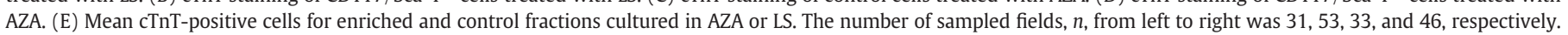
Values represent mean \pm SEM, and significant differences are ${ }^{*} p<0.05$. There was no significant difference between the two enriched groups treated with AZA or LS.

transient duration at $50 \%$ amplitude $\left(\mathrm{TD}_{50}\right)$ over time. Fig. $4 \mathrm{C}$ shows that the average $\mathrm{TD}_{50}$ was $1.17 \pm 0.11 \mathrm{~s}$ by day 14 compared to $0.66 \pm$ 0.08 s by day 19 and $0.46 \pm 0.02$ s by day 29. Similarly, Fig. 4D shows that there was a decrease in transient duration at $90 \%\left(\mathrm{TD}_{90}\right)$ for the same time periods; the average $\mathrm{TD}_{90}$ was $2.12 \pm 0.24 \mathrm{~s}, 1.15 \pm 0.12 \mathrm{~s}$, and $0.86 \pm 0.04 \mathrm{~s}$ for days 14,19 and 29, respectively. Conversely, Fig. $4 \mathrm{E}$ shows that there was an increase in the average $\mathrm{Ca}^{2+}$ transient frequency resulting in $0.62 \pm 0.08,1.08 \pm 0.12$, and $1.14 \pm 0.06 \mathrm{~Hz}$ for days 14,19 and 29 , respectively. The number of cells and the corresponding cycles analyzed were $(10,42),(7,27)$, and $(9,76)$ for days 14,19 , and 29 , respectively.

Cells used for line scan $\mathrm{Ca}^{2+}$ transient measurements were fixed and stained for cTnT and when possible the same cell was identified on the slide for both measurements. Fig. 5 shows an example of a cell with spontaneous $\mathrm{Ca}^{2+}$ transients stained positive for cTnT. These data support the hypothesis that spontaneous $\mathrm{Ca}^{2+}$ oscillations originate from cells exhibiting a cardiac lineage.

\section{5. cTnT expression is enhanced after DHPR- $\alpha 2$ enrichment}

DHPR- $\alpha 2$ is a membrane protein present in cardiac as well as skeletal and neuronal cells. The expression of L-type $\mathrm{Ca}^{2+}$ channels is an early event in the development of cardiac myocytes [19]. To further increase the number of cTnT-positive cells in our in vitro differentiation studies, we proposed to include a DHPR- $\alpha 2$-positive selection step as a second enrichment process, thus eliminating most nonmyogenic cells. This step was performed at day 26 , after the cells had differentiated into a cardiac muscle lineage (cTnT positive). Fig. 6A 


\section{A cTinTDAPI}

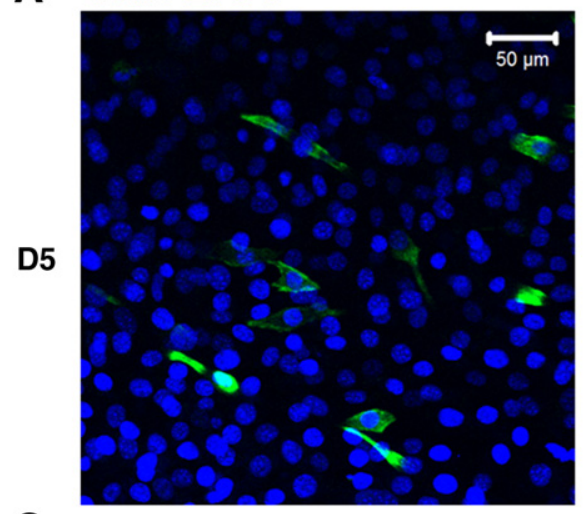

C

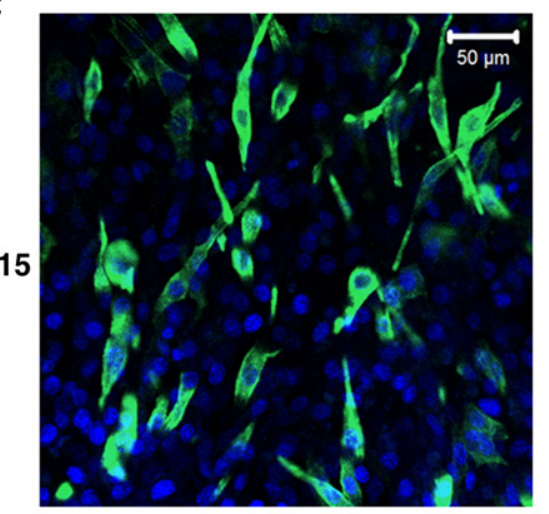

B

D9

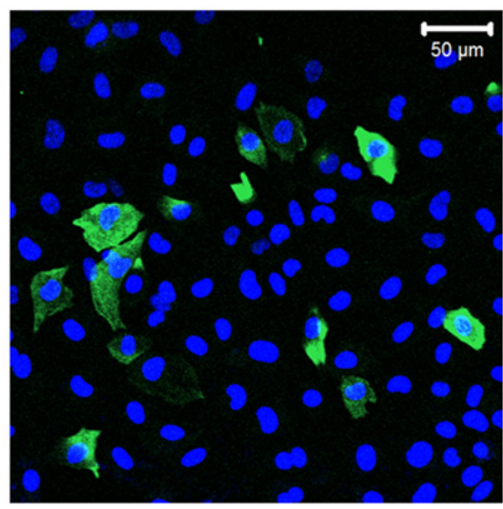

D

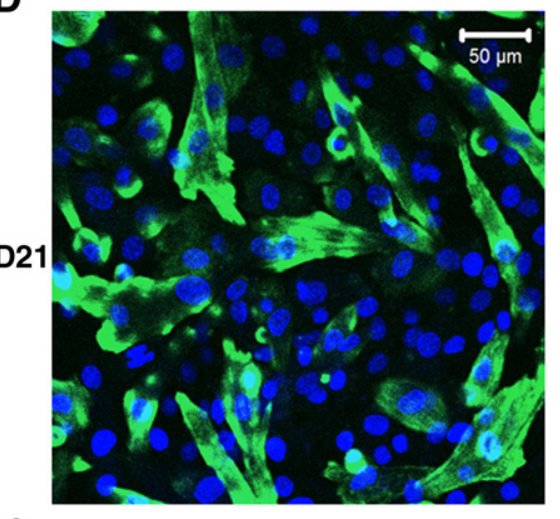

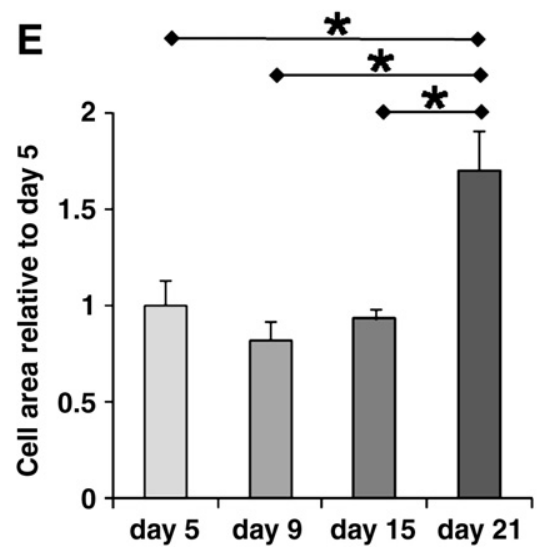

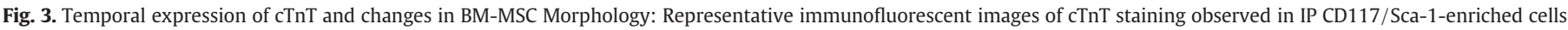

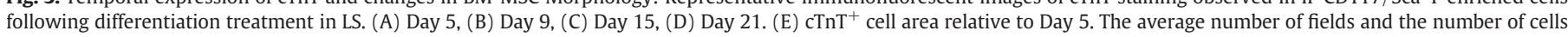
imaged per field was $(10,17),(6,20),(3,33)$, and $(4,41)$ for days $5,9,15$, and 21 , respectively.

illustrates the PCR results of the IP CD117/Sca-1-enriched cells during differentiation. These data demonstrate that amplicons for several cardiac-specific and developmental genes are observed during the early stage of differentiation. DHPR- $\alpha 2$ is also observed during differentiation and suggests that this transmembrane subunit of the L-type calcium channel is expressed commensurate with the cardiacspecific genes. We noted that there was a doublet amplicon for the DHPR- $\alpha 2$ subunit in our RT-PCR analysis. The primers used for the PCR did not distinguish between cardiac and skeletal muscle forms of the subunit suggesting that myogenic development for both skeletal and cardiac muscle probably occurred in our cultures. Fig. 6B shows the results of DHPR- $\alpha 2$ staining of CD117/Sca- ${ }^{+}$cells after 20 days in differentiating media and B shows the DHPR- $\alpha 2$ FACS analysis of CD117/Sca-1-enriched cells for the same time period. After having sorted the differentiated cells described in Fig. 6C, the cells were replated and cultured in MEM with 5\% FBS and ITS, and the sorted cells recovered and easily adhered to the plate within the first $24 \mathrm{~h}$.
These DHPR- $\alpha 2$-enriched cells were cultured for an additional 30 days and fixed for immunofluorescent cTnT staining (Fig. 6D). Cell counts show that there was a significant increase in the percent of cTnT-positive cells $54 \pm 3 \%(n=45)$ for the DHPR- $\alpha 2$-enriched compared to $28 \pm 2 \%(n=33)$ in the CD117/Sca-1-enriched and $12 \pm 2 \%(n=46)$ in the control cells shown in Fig. 6E. Our control experiments (Fig. S7) show that if differentiated cells with $2 \%$ FBS are kept in culture for 56 days or if they are lifted at day 26 and replated for an additional 30 days, the level of cTnT expression is unchanged but is still significantly lower than the cTnT expression observed in DHPR- $\alpha 2$-enriched cells.

We observed spontaneous $\mathrm{Ca}^{2+}$ oscillations in the DHPR- $\alpha 2^{+}$ cells and were able to identify spontaneous $\mathrm{Ca}^{2+}$ transients in CTnTpositive cells. It is interesting to note that we were able to observe spontaneous synchronized cycling and movement on some DHPR- $\alpha 2$ cultured plates 30 days after seeding. Supplemental Video 1 shows a group of differentiated DHPR- $\alpha 2$-enriched cells in motion and 
A

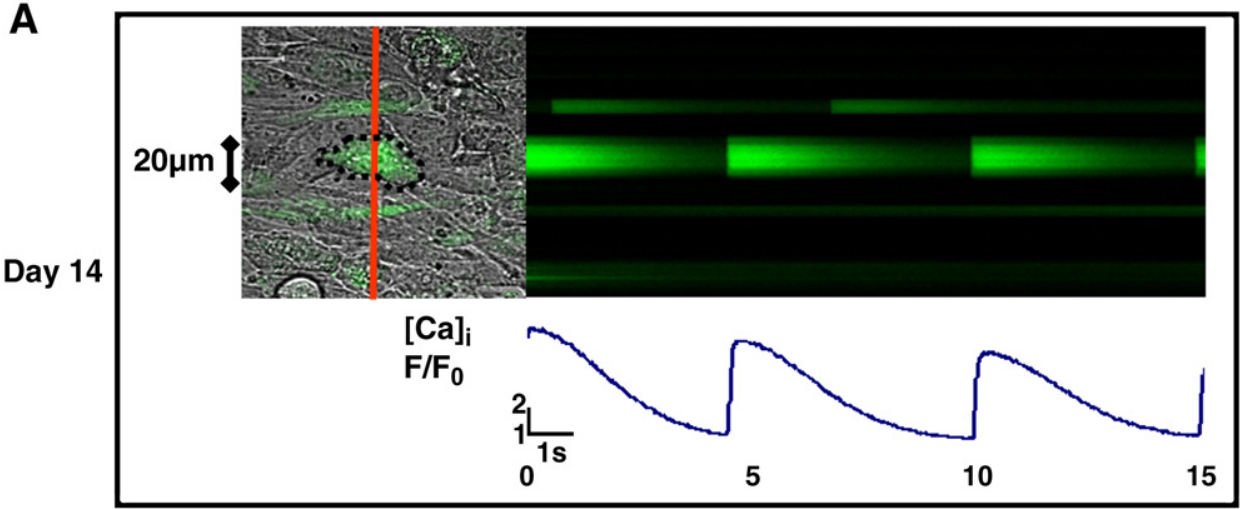

B

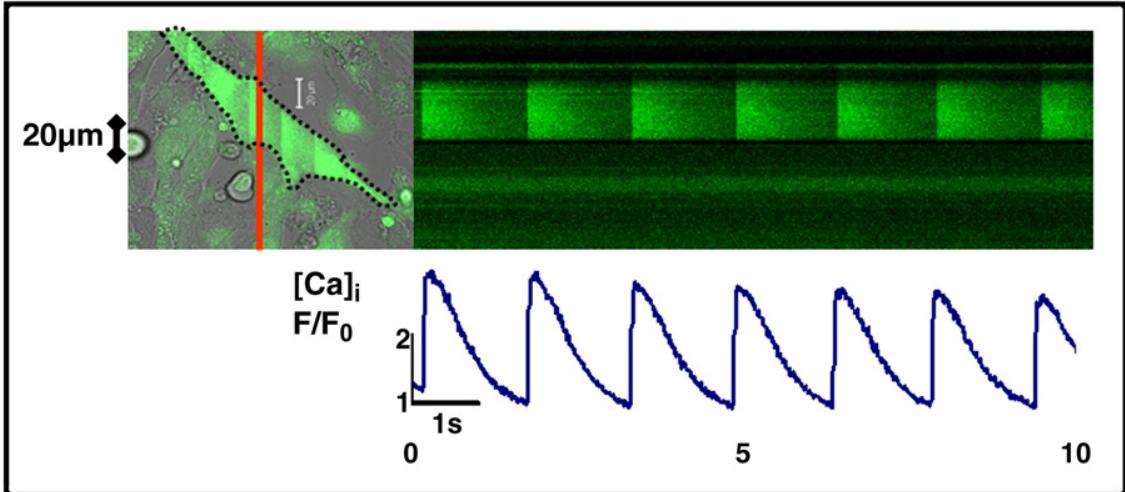

C

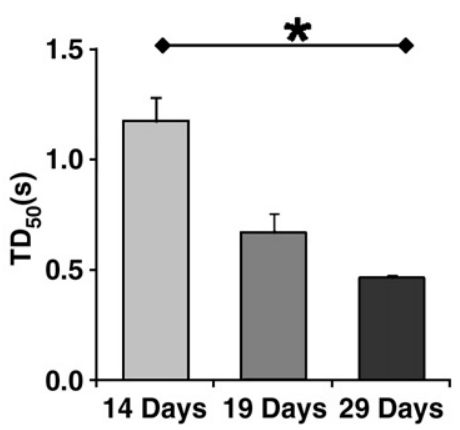

D

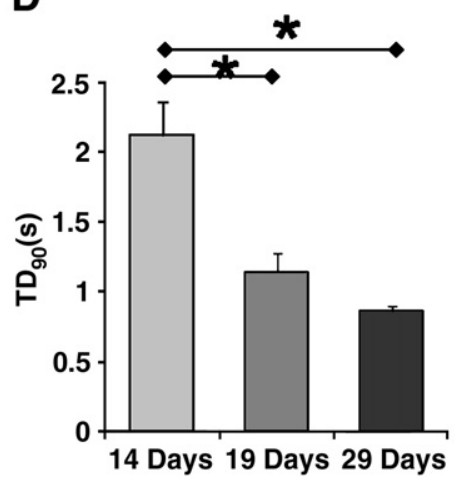

E

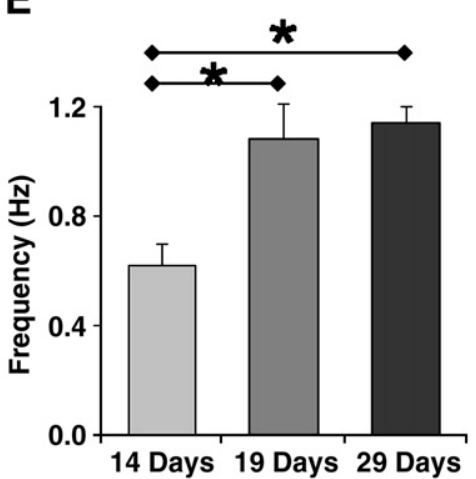

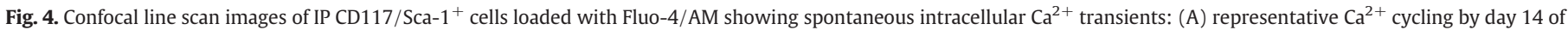

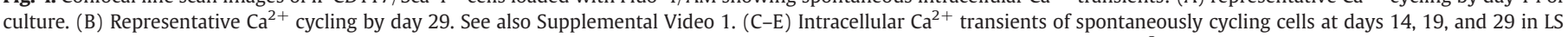

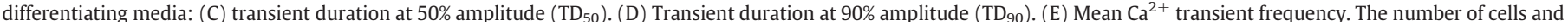

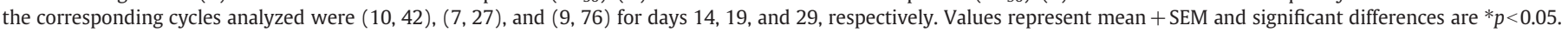

spontaneously cycling $\mathrm{Ca}^{2+}$ and Fig. S10 shows positive cTnT staining of the same moving cells. In addition, Video-2 shows another group of differentiated DHPR- $\alpha 2$-enriched cells in motion after stimulated with a 1-ms pulse of $80 \mathrm{~V}$ after 30 days in LS culture (for viewing purposes, the video speed was increased compared to actual time).

\subsection{Intracellular $\mathrm{Ca}^{2+}$ transients in DHPR- $\alpha 2$-enriched cells}

The L-type $\mathrm{Ca}^{2+}$ channel is activated by depolarizing voltage change during the upstroke of the cardiac action potential. To determine if the DHPR- $\alpha 2$ enrichment process and the replating affected the functional performance of the cells, we measured their intracellular $\mathrm{Ca}^{2+}$ transients 30 days after the enrichment. Cells exhibited $\mathrm{Ca}^{2+}$ transients upon field stimulation supporting the hypothesis that the DHPR- $\alpha 2$-enriched cells are electrically excitable cells. We compared the spontaneous $\mathrm{Ca}^{2+}$ transients previously recorded to frequency matched stimulated $\mathrm{Ca}^{2+}$ transients. Fig. 7 shows the results of the statistical analysis of spontaneous and stimulated intracellular $\mathrm{Ca}^{2+}$ transients of CD117/Sca-1 and DHPR$\alpha 2$ s-enriched cells after differentiation in LS and cultured for 30 days in MEM $+5 \%$ FBS and ITS media. The average $\mathrm{TD}_{50}$ was $0.57 \pm 0.05 \mathrm{~s}$ for the spontaneously cycling cells and $0.43 \pm 0.02 \mathrm{~s}$ for the stimulated cells. The average $\mathrm{TD}_{90}$ was $0.99 \pm 0.09$ and $0.72 \pm 0.03 \mathrm{~s}$ for the spontaneous and stimulated cells, respectively. The average TA $\left(\Delta F / F_{0}\right)$ was $3.44 \pm 0.4$ and $2.84 \pm 0.3$ for spontaneous and stimulated cells, respectively. $\mathrm{Ca}^{2+}$ transient examples are given in Fig. S9. Overall the $\mathrm{Ca}^{2+}$ transient duration compares well with those described for embryonic mouse cardiomyocytes [16]. Fluo-4/AMloaded DHPR- $\alpha 2$-enriched BM-MSCs were also electrically stimulated in culture and sequentially incubated with either $40 \mu \mathrm{M}$ nifedipine to specifically block the L-type $\mathrm{Ca}^{2+}$ channel or $100 \mu \mathrm{M}$ cadmium to block calcium entry via both the L-type and T-type $\mathrm{Ca}^{2+}$ channels. Our data demonstrate (Fig. 8 and Supplemental Video 3) that some of the differentiated and enriched cells were sensitive to the addition of nifedipine, suggesting that BM-MSCs did develop functional L-type 

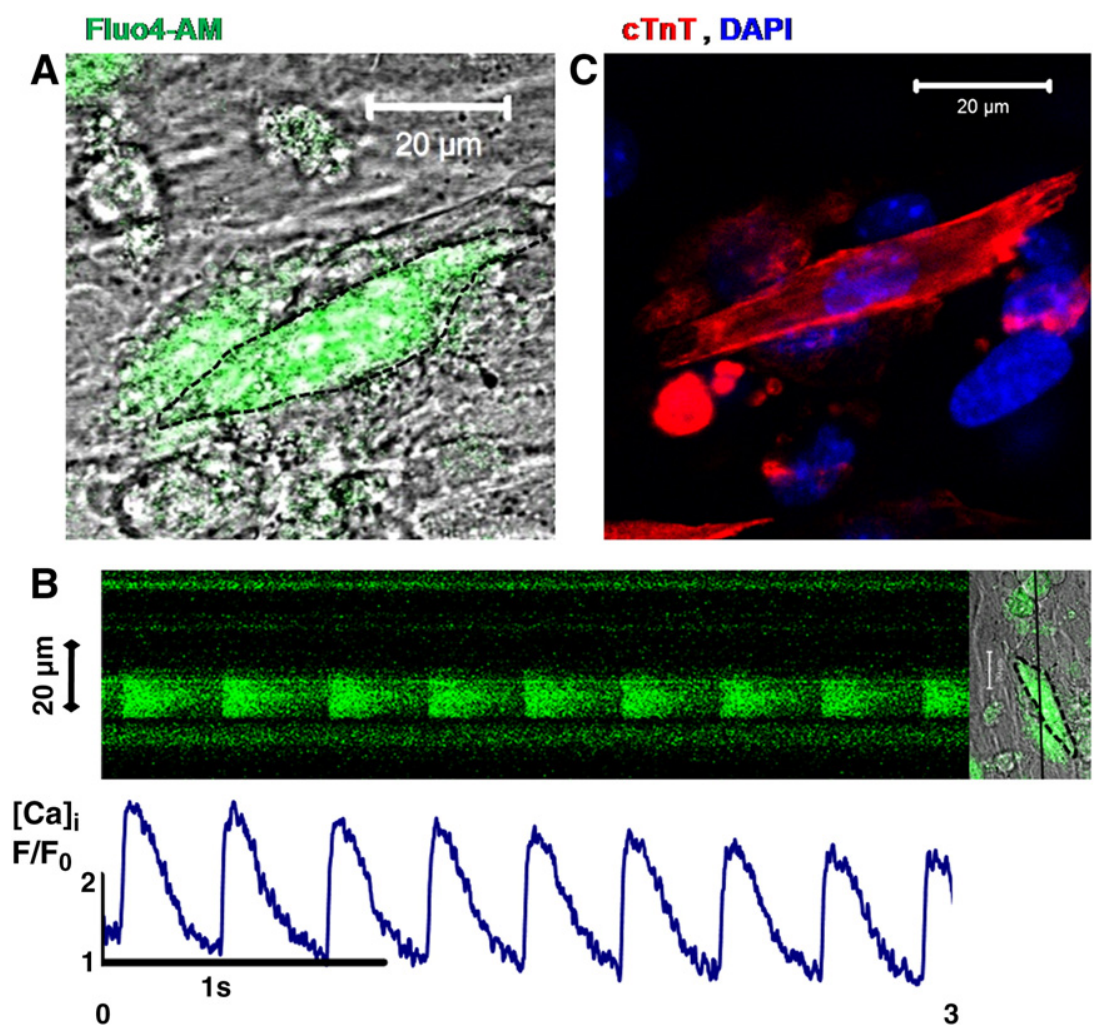

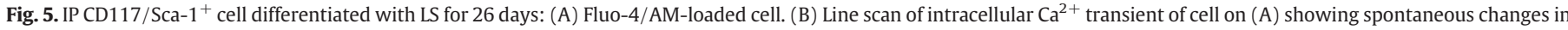
$[\mathrm{Ca}]_{\mathrm{i}}$. (C) After fixation and staining, cell on (A) was identified on the plate and verified to be $\mathrm{cTnT}^{+}$.

calcium channels while transients in other cells persisted. When exposed to cadmium, all fluo-4/AM generated calcium transients were abolished (Supplemental Video 4).

\section{Discussion}

We have demonstrated that cardiomyogenesis in adherent bone marrow-derived Lin $^{-}$cells is greatly enhanced when differentiation is initiated in intermediate passage cells (P8-P12) in low serum following enrichment for the stem cell markers CD117/Sca-1. The percent of cells expressing cardiac-specific TnT was significantly elevated compared to those previously reported for bone marrowderived mesenchymal cells [20]. Most strikingly, a large number of these myogenic cells also displayed spontaneous calcium transients by day 12 in culture and reduced transient amplitude durations between days 14 and 29. This temporal change in calcium transients also correlated with the most significant changes in cell morphology (between days 15 and 21 in culture). CD117/Sca- $1^{+}$cells cultured in differentiating media also expressed DHPR- $\alpha 2$ by day 15 . When these cells were further enriched for DHPR- $\alpha 2$ and re-seeded for an additional 30 days in culture, the percent of cells expressing cTnT doubled compared to CD117/Sca- ${ }^{+}$BM-MSC-enriched cells alone. We observed that the number of $\mathrm{cTnT}^{+}$cells did not increase when we extended the time in culture for an additional 30 days without DHPR- $\alpha 2$ enrichment. Similarly, lifting and replating the cells for an additional 30 days in culture did not improve the expression of cTnT of $\mathrm{CD} 117 / \mathrm{Sca}-1^{+}$cells. Therefore, we conclude that further enrichment of cells for a muscle-specific protein (DHPR- $\alpha 2$ ) establishes a culture of highly differentiated cells that are more likely to exhibit a myogenic lineage. Previous studies demonstrate that induction of the myogenic program can be initiated in bone marrow-derived mesenchymal stem cells but this has been limited to changes in protein expression [6-9,20-23] or studies in which expression of muscle-specific proteins in MSC have been induced by TGF- $\beta$ [6],
Wnt-mediated signaling [20], and co-culturing with cardiac myocytes [10-13,22].

The protocol in the present study included an enrichment step after $\mathrm{Lin}^{-} \mathrm{BM}-\mathrm{MSC}$ were in culture for an extended period of time (P8-P12). In contrast, enrichment for $\mathrm{CD} 117 / \mathrm{Sca}-1^{+}$at the time of bone marrow harvest results in a significant population of hematopoietic stem cells that have been shown to lack myogenic potential [24-26]. Furthermore, CD117 expression decreases over time and passage in culture [2, 6] due either to decreased expression of the receptor or loss of nonadherent cells with passage. We observed these same changes in both our EP and LP cells. EP cells did not adhere well to the culture plate containing our differentiation media and LP cells lost expression of CD117/Sca-1 over time. Thus, we cannot conclude from our experiments that passage number has an effect on the potential for CD117/ Sca- $1^{+}$cells to develop into a myogenic lineage.

Observations of differentiated cells revealed large growth areas with tubular-shaped cell formation and multi-nucleated cells together with large growth areas of non-myogenic cells. Thus, after testing for the presence of DHPR- $\alpha 2$ in the differentiated cultures, we reasoned that further enrichment for DHPR- $\alpha 2$ protein might produce cultures with higher myogenic potential than CD117/Sca-1-enriched cells alone. This second enrichment step resulted in an increase in CTnTpositive cells. We also noted that there was a doublet amplicon for the DHPR- $\alpha 2$ subunit in our RT-PCR analysis. The primers used for the PCR did not distinguish between cardiac and skeletal muscle forms of the subunit suggesting that myogenic development for both skeletal and cardiac muscle probably occurred in our cultures.

The presence of calcium channels and ionic currents in undifferentiated bone marrow mesenchymal stem cells has been previously reported $[27,28]$. We were able to identify a nifedipine-sensitive isoform of the L-type $\mathrm{Ca}^{2+}$ channel in cells enriched for the CD117/ Sca-1 cell surface markers and demonstrated that differentiated cells displayed spontaneous $\mathrm{Ca}^{2+}$ transients. This is the first observation, to our knowledge, in which differentiated BM-MSC displayed persistent 
A
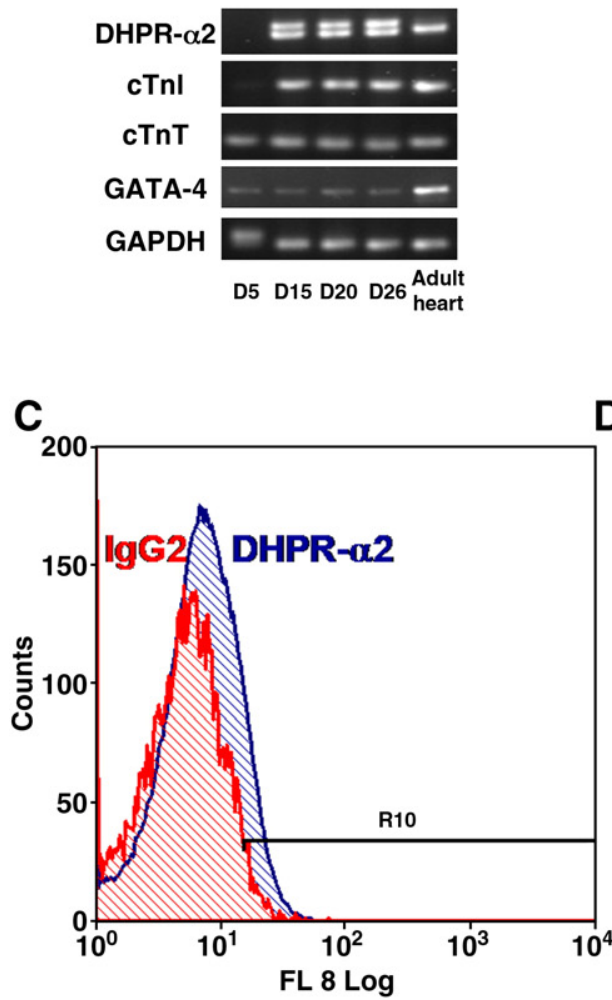

\section{B DHHPR-@2 DAPI}

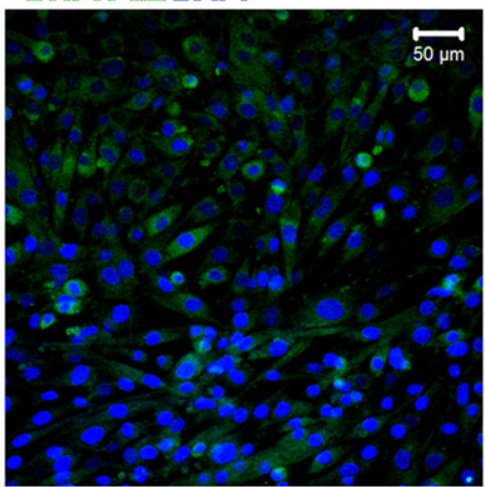

D cTnT DAPI

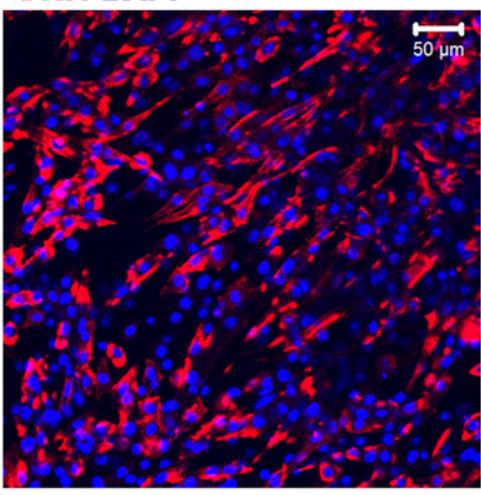

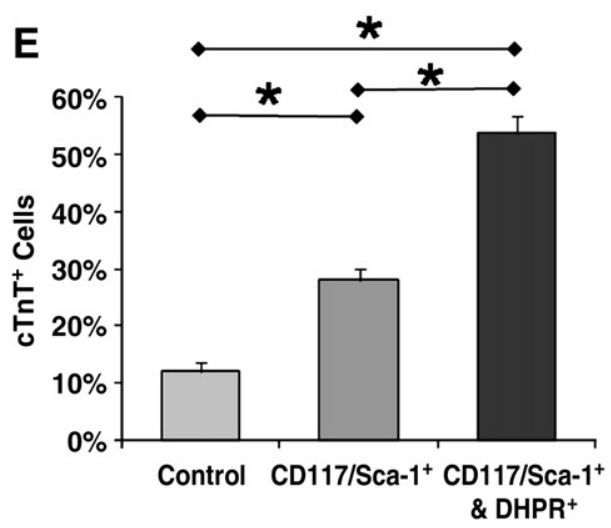

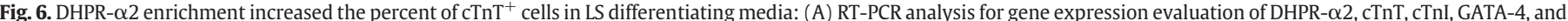

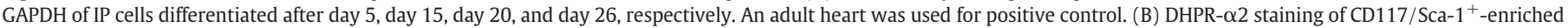

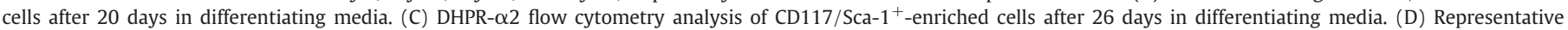

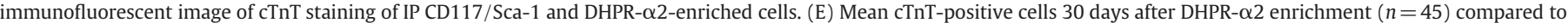
control $(n=46)$ and CD117/Sca- $1^{+}(n=33)$ cells. Values represent mean \pm SEM, and significant differences are $* p<0.05$.
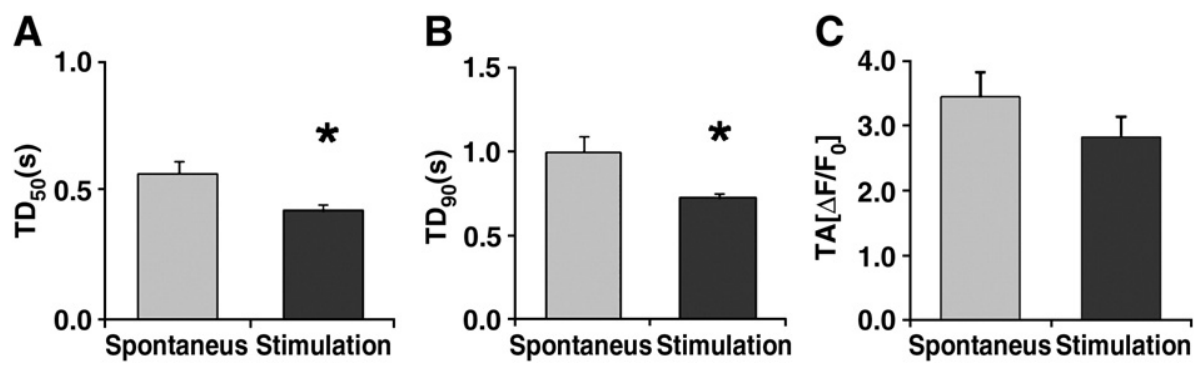

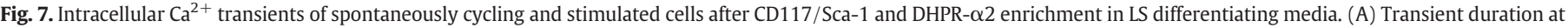

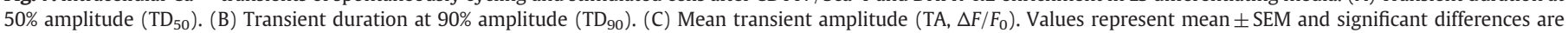
${ }^{*} p<0.05$. The number of cells and the corresponding cycles analyzed were $(6,32)$ and $(5,26)$. Refer to supplemental data for representative Ca ${ }^{2+}$ transient examples. 


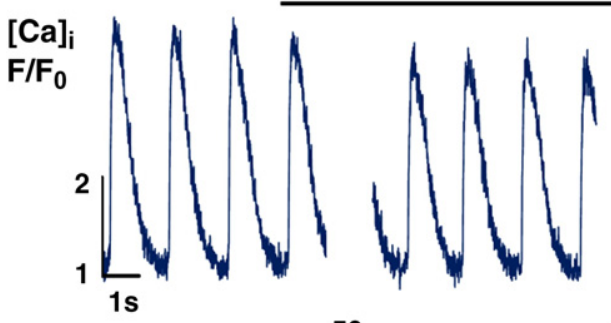

50

B

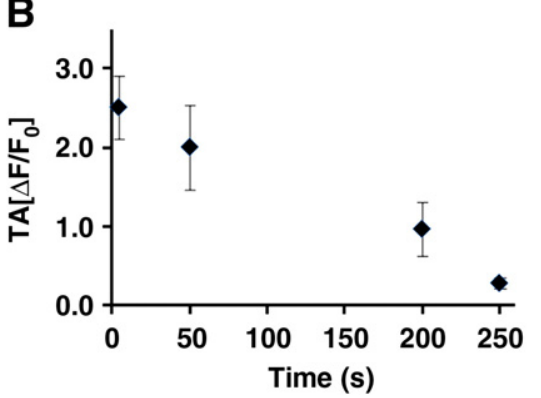

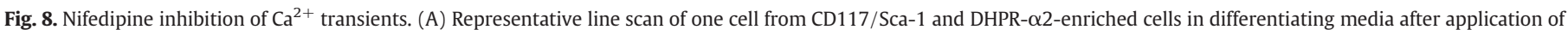

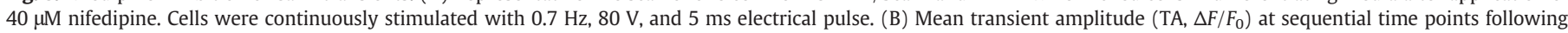

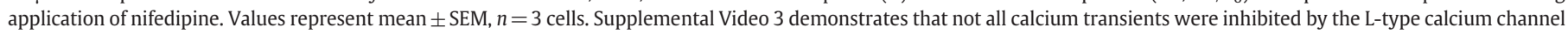
blocker.

and robust $\mathrm{Ca}^{2+}$ oscillations in a large percentage of BM-MSC cultured in the absence of cardiomyocytes or cardiomyocyte-conditioned media. Kawano et al. [28] demonstrated that undifferentiated human mesenchymal stem cells displayed spontaneous $\mathrm{Ca}^{2+}$ oscillations but that the primary pathway of $\mathrm{Ca}^{2+}$ entry into the cell was from voltage-independent $\mathrm{Ca}^{2+}$ channels which are found in nonexcitable cells.

We have demonstrated evidence of L-type $\mathrm{Ca}^{2+}$ channels, with our observations of DHPR- $\alpha 2$ in enriched and differentiated BM-MSC. Furthermore, our $\mathrm{Ca}^{2+}$ transients could be initiated by electrical stimulation in cells enriched for the channel protein (Fig. S9). In addition, we have demonstrated that a population of our DHPR- $\alpha 2$ enriched cells has functional L-type $\mathrm{Ca}^{2+}$ channels because we were able to inhibit the $\mathrm{Ca}^{2+}$ transients with application of nifedipine, a specific L-type $\mathrm{Ca}^{2+}$ channel blocker. Taken together, these data suggest that $\mathrm{Ca}^{2+}$ entry into cells in the present study could have been directed by voltage-sensitive L-type $\mathrm{Ca}^{2+}$ channels, characteristic of cells undergoing myogenic differentiation.

One of the most striking findings in our study is that the frequency of the $\mathrm{Ca}^{2+}$ transients increased over time and that the transient amplitude duration of CD117/Sca-1-enriched cells decreased from 14 to 29 days in culture. Evidence from studies in embryonic-derived cardiomyocytes [16] and developing heart [19,29] suggests that as the cardiomyocyte matures from neonatal to adult, $\mathrm{Ca}^{2+}$ entry, storage, and release is altered by synthesis and maturation of $\mathrm{SR}_{-}-\mathrm{Ca}^{2+}$ release channels and voltage-sensitive channels. The change in $\mathrm{Ca}^{2+}$ kinetics observed in our cells over time is consistent with the observed changes in the maturing cardiomyocyte.

In conclusion, we found that differentiating media containing low serum was equally effective in inducing cTnT expression and spontaneous calcium transients compared to the DNA methyltransferase inhibitor, 5-azacytidine. In addition, cTnT expression and spontaneous calcium transients in BM-MSC were more prevalent in IP cells following CD117/Sca-1 enrichment compared to unenriched Lin $^{-}$cells and variability in the calcium transients decreased as length of time in differentiating media increased. The increase in spontaneous calcium cycling frequency, decrease in transient duration with time, and identification of enriched cells with functional L-type $\mathrm{Ca}^{2+}$ channels suggests a progressive maturation of the calcium regulatory mechanisms of the cell and thus greater myogenic development. Taken together, these data demonstrate that specific cell enrichment steps and early cardiac lineage development in culture may improve the potential of BM-MSC for regenerative therapy.

\section{Acknowledgements}

The authors thank Nidhi Kapur for her initial assistance with the Fluo-4 AM Ca ${ }^{2+}$ transient measurements and Jose Carlos Lopez Dominguez for his assistance with statistical analysis of the data. This work was funded by the Illinois Department of Public Health (P.I. D.L. Geenen), the NHLBI (R01 HL071046; P.I. D.L. Geenen), and the MDA (P.I. J. García). Dr. Grajales is the recipient of a 2008 American Heart Association CVD Student Scholarship.

\section{Appendix A. Supplementary data}

Supplementary data associated with this article can be found, in the online version, at doi:10.1016/j.yjmcc.2009.12.022.

\section{References}

[1] Cimini M, Fazel S, Zhuo S, Xaymardan M, Fujii H, Weisel RD, et al. c-kit dysfunction impairs myocardial healing after infarction. Circulation 2007;116(11 Suppl): I77-82.

[2] Li M, Naqvi N, Yahiro E, Liu K, Powell PC, Bradley WE, et al. c-kit is required for cardiomyocyte terminal differentiation. Circ Res 2008;102(6):677-85.

[3] Lutz M, Rosenberg M, Kiessling F, Eckstein V, Heger T, Krebs J, et al. Local injection of stem cell factor (SCF) improves myocardial homing of systemically delivered ckit+ bone marrow-derived stem cells. Cardiovasc Res 2008;77(1):143-50.

[4] Okada S, Nakauchi H, Nagayoshi K, Nishikawa S, Miura Y, Suda T. In vivo and in vitro stem cell function of c-kit- and Sca-1-positive murine hematopoietic cells. Blood 1992;80(12):3044-50.

[5] Thoren LA, Liuba K, Bryder D, Nygren JM, Jensen CT, Qian H, et al. Kit regulates maintenance of quiescent hematopoietic stem cells. J Immunol 2008;180(4): 2045-53.

[6] Li TS, Komota T, Ohshima M, Qin SL, Kubo M, Ueda K, et al. TGF-beta induces the differentiation of bone marrow stem cells into immature cardiomyocytes. Biochem Biophys Res Commun 2008;366(4):1074-80.

[7] Hakuno D, Fukuda K, Makino S, Konishi F, Tomita Y, Manabe T, et al. Bone marrowderived regenerated cardiomyocytes (CMG Cells) express functional adrenergic and muscarinic receptors. Circulation 2002;105(3):380-6. 
[8] Makino S, Fukuda K, Miyoshi S, Konishi F, Kodama H, Pan J, et al. Cardiomyocytes can be generated from marrow stromal cells in vitro. J Clin Invest 1999;103(5): 697-705.

[9] Shiota M, Heike T, Haruyama M, Baba S, Tsuchiya A, Fujino H, et al. Isolation and characterization of bone marrow-derived mesenchymal progenitor cells with myogenic and neuronal properties. Exp Cell Res 2007;313(5):1008-23.

[10] Li Z, Gu TX, Zhang YH. Hepatocyte growth factor combined with insulin like growth factor-1 improves expression of GATA-4 in mesenchymal stem cells cocultured with cardiomyocytes. Chin Med J (Engl) 2008;121(4):336-40.

[11] Muscari C, Bonafe F, Carboni M, Govoni M, Stanic I, Gamberini C, et al Difluoromethylornithine stimulates early cardiac commitment of mesenchymal stem cells in a model of mixed culture with cardiomyocytes. J Cell Biochem 2008;103(4):1046-52.

[12] Rota M, Kajstura J, Hosoda T, Bearzi C, Vitale S, Esposito G, et al. Bone marrow cells adopt the cardiomyogenic fate in vivo. Proc Natl Acad Sci U S A 2007;104(45): 17783-8.

[13] Yoon J, Choi SC, Park CY, Choi JH, Kim YI, Shim WJ, et al. Bone marrow-derived side population cells are capable of functional cardiomyogenic differentiation. Mol Cells 2008;25(2):216-23.

[14] Passier R, Oostwaard DW, Snapper J, Kloots J, Hassink RJ, Kuijk E, et al. Increased cardiomyocyte differentiation from human embryonic stem cells in serum-free cultures. Stem Cells 2005;23(6):772-80.

[15] Boomsma RA, Swaminathan PD, Geenen DL. Intravenously injected mesenchymal stem cells home to viable myocardium after coronary occlusion and preserve systolic function without altering infarct size. Int J Cardiol 2007;122 (1):17-28.

[16] Kapur N, Mignery GA, Banach K. Cell cycle-dependent calcium oscillations in mouse embryonic stem cells. Am J Physiol Cell Physiol 2007;292(4):C1510-8.

[17] Epting CL, King FW, Pedersen A, Zaman J, Ritner C, Bernstein HS. Stem cell antigen1 localizes to lipid microdomains and associates with insulin degrading enzyme in skeletal myoblasts. J Cell Physiol 2008;217(1):250-60.

[18] van de Rijn M, Heimfeld S, Spangrude GJ, Weissman IL. Mouse hematopoietic stem-cell antigen Sca- 1 is a member of the Ly- 6 antigen family. Proc Natl Acad Sci U S A 1989;86(12):4634-8.
[19] Snopko RM, Aromolaran AS, Karko KL, Ramos-Franco J, Blatter LA, Mejia-Alvarez R. Cell culture modifies $\mathrm{Ca} 2+$ signaling during excitation-contraction coupling in neonate cardiac myocytes. Cell Calcium 2007;41(1):13-25.

[20] Bedada FB, Braun T. Partial induction of the myogenic program in noncommitted adult stem cells. Cells Tissues Organs 2008;188(1-2):189-201.

[21] Martin-Rendon E, Sweeney D, Lu F, Girdlestone J, Navarrete C, Watt SM. 5Azacytidine-treated human mesenchymal stem/progenitor cells derived from umbilical cord, cord blood and bone marrow do not generate cardiomyocytes in vitro at high frequencies. Vox Sang 2008;95(2):137-48.

[22] Shim WS, Jiang S, Wong P, Tan J, Chua YL, Tan YS, et al. Ex vivo differentiation of human adult bone marrow stem cells into cardiomyocyte-like cells. Biochem Biophys Res Commun 2004;324(2):481-8.

[23] Tokcaer-Keskin Z, Akar AR, Ayaloglu-Butun F, Terzioglu-Kara E, Durdu S, Ozyurda $\mathrm{U}$, et al. Timing of induction of cardiomyocyte differentiation for in vitro cultured mesenchymal stem cells: a perspective for emergencies. Can J Physiol Pharmacol 2009;87(2):143-50.

[24] Agbulut O, Menot ML, Li Z, Marotte F, Paulin D, Hagege AA, et al. Temporal patterns of bone marrow cell differentiation following transplantation in doxorubicininduced cardiomyopathy. Cardiovasc Res 2003;58(2):451-9.

[25] Murry CE, Soonpaa MH, Reinecke H, Nakajima H, Nakajima HO, Rubart M, et al. Haematopoietic stem cells do not transdifferentiate into cardiac myocytes in myocardial infarcts. Nature 2004;428(6983):664-8.

[26] Scherschel JA, Soonpaa MH, Srour EF, Field LJ, Rubart M. Adult bone marrowderived cells do not acquire functional attributes of cardiomyocytes when transplanted into peri-infarct myocardium. Mol Ther 2008;16(6):1129-37.

[27] Heubach JF, Graf EM, Leutheuser J, Bock M, Balana B, Zahanich I, et al. Electrophysiological properties of human mesenchymal stem cells. J Physiol 2004;554(Pt 3):659-72.

[28] Kawano S, Shoji S, Ichinose S, Yamagata K, Tagami M, Hiraoka M. Characterization of $\mathrm{Ca}(2+)$ signaling pathways in human mesenchymal stem cells. Cell Calcium 2002;32(4):165-74.

[29] Escobar AL, Ribeiro-Costa R, Villalba-Galea C, Zoghbi ME, Perez CG, Mejia-Alvarez R. Developmental changes of intracellular $\mathrm{Ca} 2+$ transients in beating rat hearts. Am J Physiol Heart Circ Physiol 2004;286(3):H971-8. 